\title{
Kajian Preferensi Stakeholder Terhadap Kebijakan Jalan Berbayar dan Parkir Progresif Studi Kasus di Wilayah Urban dan Sub Urban, Kota Balikpapan
}

\author{
*Elin Diyah Syafitri, Arif Wismadi, \\ Perencanaan Wilayah dan Kota, Institut Teknologi Kalimantan \\ *elindiyahs@itk.ac.id
}

\section{INFO ARTIKEL}

Riwayat Artikel:

Diterima:21-01- 2019

Disetujui: 02-03 - 2019

\section{Kata Kunci:}

Preferensi

Stakeholder

Jalan Berbayar

Parkir Progresif

\section{A. LATAR BELAKANG}

Penyediaan infrastruktur jalan dan jembatan selalu diiringi dengan pertumbuhan volume lalu lintas, hal ini jika tidak diimbangi dengan manajemen transportasi yang baik akan menimbulkan masalah baru khususnya bagi kota-kota yang sedang berkembang. Masalah yang dapat terjadi, seperti peningkatan jumlah kendaraan pribadi [1], yang dapat menyebabkan kemacetan [2], polusi, dan sulitnya akses bagi masyarakat yang tinggal di wilayah tersebut. Untuk mengendalikan volume lalu lintas tersebut, diperlukan pendekatan manajemen transportasi. Salah satunya dengan Transport Demand Management [3]. TDM bertujuan untuk menciptakan sistem transportasi yang berkelanjutan dengan memaksimalkan penggunaan transportasi umum dan kendaraan non-motorized [4]. Ada empat klasifikasi utama dalam TDM yaitu melalui peningkatan mobilitas, kebijakan ekonomi, kebijakan tata guna lahan, dan kebijakan-kebijakan lain seperti manajemen bus sekolah dan bus pariwisata) [5]. Beberapa penelitian di negara maju menggambarkan bahwa melalui kebijakan ekonomi seperti penerapan jalan berbayar, biaya kemacetan dan biaya parkir progresif dianggap lebih efektif dalam mengurangi penggunaan kendaraan pribadi [6]. Bahwa Kota atau negara dengan penggunaan kendaraan pribadi yang tinggi [7], lebih efektif jika mengimplementasikan kebijakan ekonomi berbayar untuk mengurangi penggunaan kendaraan pribadi [8].

Beberapa Kota besar di Indonesia telah menerapkan beberapa upaya manajemen permintaan transportasi melalui kebijakan ekonomi, seperti penerapan biaya parkir progresif dan rencana penerapan jalan berbayar (ERP) di Jakarta. Kedua kebijakan ini bertujuan untuk meningkatkan efisiensi dan efektivitas sistem transportasi perkotaan. Bagaimana bila kebijakan ekonomi; parkir progresif dan jalan berbayar ini diterapkan pada kota-kota berkembang di Indonesia, terutama untuk mengendalikan volume jumlah lalu lintas, khususnya kendaraan pribadi dan mendorong agar masyarakat berpindah menggunakan angkutan umum? Untuk mendukung penerapan TDM melalui kebijakan ekonomi seperti jalan berbayar dan parkir progresif di kota-kota berkembang, sangat diperlukan penerimaan (respon) oleh para pemangku kepentingan (stakeholder) sehingga apabila diterapkan dapat 
memberikan manfaat yang efektif dan sesuai tangga, dan tukang parkir), kelompok pengambil kepentingan [9]. Setiap stakeholder memiliki keputusan/decision maker (Badan Perencanaan dan penerimaan (respon) yang berbeda-beda karena para Pembangunan Daerah, Dinas Perhubungan, Dinas stakeholder yang berbeda memiliki tujuan yang beragam, Pekerjaan Umum) dan kelompok yang dapat yang tidak pernah terintegrasi [10]. Hal ini apabila tidak mempengaruhi/influence group (peneliti atau akademisi). ditangani dengan baik, akan menimbulkan konflik Subjek penelitian terdiri dari perempuan atau laki-laki, antara stakeholder.

Tujuan dari penelitian ini untuk menentukan instrumen manakah antara jalan berbayar dan parkir progresif, yang paling diterima oleh para stakeholder di wilayah urban dan sub-urban. Respon dari para stakeholder dalam suatu pelaksanaan kebijakan transportasi (jalan berbayar dan parkir progresif) sangat dibutuhkan untuk mengetahui kepentingan dan pengaruh para stakeholder terhadap kebijakan tersebut. Hasilnya, ketika terjadi konflik akibat perbedaan kepentingan dan pengaruh, pemerintah dan perencana telah memiliki strategi penanganan yang tepat dan sesuai dengan kepentingan masing-masing stakeholder. Penelitian ini mengumpulkan 100 stakeholder sebagai responden di wilayah perkotaan dan sub-urban. Data ini meliputi karakteristik sosial, ekonomi, dan preferensi dari para stakeholder terhadap penerapan kebijakan jalan berbayar dan kebijakan parkir progresif. Penelitian ini menganalisis data dengan: metode Borda count (analisis deskriptif), dan metode stated preference (analisis regresi logistic biner statistic) untuk menentukan pilihan responden terhadap preferensi kebijakan jalan berbayar atau kebijakan parkir progresif.

\section{B. METODE PENELITIAN}

\section{Desain Survey}

Untuk mendapatkan data tentang respon dan kepentingan stakeholder terhadap penerapan "kebijakan jalan berbayar" dan "kebijakan parkir progresif", dilakukan dengan memberikan kuesioner di wilayah studi. Ada tiga bagian dalam kuesioner yang harus diisi oleh responden sebagai stakeholder. Bagian pertama yaitu identitas responden yang bertujuan untuk melihat karkteristik social, ekonomi responden. Bagian kedua yaitu preferensi responden terhadap pemilihan "kebijakan jalan berbayar" dan "kebijakan parkir progresif”. Pada bagian kedua ini, responden memberikan rangking (rangking 1 untuk yang lebih dipilih dan rangking 2 untuk yang tidak dipilih) terhadap 2 kebijakan tersebut sesuai dengan yang mereka anggap lebih penting. Bagian ketiga, berisi stated preferensi responden terhadap 2 kebijakan tersebut. Hasil dari data kuesioner akan di olah dan dianalisis menggunakan analisis deskriptif dan analisis kuantitatif Metoda yang dipakai dalam penelitian ini berupa langkah kerja serta rangkaian kegiatan sebagai berikut:

\section{Subjek Penelitian}

Subjek penelitian ini adalah stakeholder yang terkena dampak langsung dan tinggal di wilayah urban dan sub urban. Stakeholder dibagi menjadi 3 kelompok yaitu kelompok penerima manfaat/beneficiaries (pelajar, karyawan swasta \& pegawai negri, pedagang, ibu rumah dengan usia sekitar 15 tahun ke atas. Penelitian ini mengambil jumlah sampel sebanyak 100 responden.

\section{Lokasi Penelitian}

Penelitian ini dilakukan di Kota Balikpapan, Provinsi Kalimantan Timur. Kota ini dipilih karena termasuk dalam kawasan strategis nasional di Indonesia, dimana pembangunan infrastruktur seperti jalan toll "Balikpapan-Samarinda" dan jembatan "Pulau Balang" berfungsi sebagai infrastruktur pendukung pengembangan kawasan yaitu sebagai pusat industri dan perkebunan di Provinsi Kalimantan.

\section{Metode Pengukuran Data}

Pertama dilakukan dengan cara melihat kebijakan mana yang lebih banyak di pilih antara "kebijakan jalan berbayar" dan "kebijakan parkir progresif" oleh stakeholder menggunakan metode borda count dan analisis state preference, metode borda count dilakukan dengan cara teknik pembobotan, sedangkan analisis state preference menggunakan analisis regresi biner dengan bantuan SPSS. Setelah menghasilkan satu kebijakan yang lebih diterima stakeholder, selanjutnya dilakukan analisis stakeholder melalui assesmen terhadap kepentingan dan pengaruh stakeholder.

\section{Analisis Data}

Analisis stakeholder dilakukan mengikuti tahapan analisis yang meliputi; 1) merumuskan tujuan dilakukannya analisis kebijakan, 2) identifikasi pengelompokan dan pengategorian stakeholder, 3) Assesmen terhadap atribut stakeholder, 4) menyimpulkan dan menganalisis hasil dari temuan asessmen, dan 5) mengintegrasikan perencanaan kebijakan/proyek (Groenendijk, 2003)[11]. Tingkat kepentingan dan pengaruh stakeholder diklasifikasikan menjadi rendah, sedang dan tinggi [12].

\section{HASIL DAN PEMBAHASAN}

\section{Analisis Pemilihan "Kebijakan Jalan Berbayar dan Parkir Progresif}

Peneliti menemukan dengan menggunakan metode borda count, mayoritas nilai tertinggi pilihan stakeholder ada pada kebijakan parkir progresif. Tabel 1. membandingkan hasil perhitungan antara pemilihan "kebijakan jalan berbayar" dengan "kebijakan parkir progresif" di wilayah urban dan sub urban.

Tabel 1

Hasil Perhitungan Metode Borda Count di Urban dan Sub urban area

\begin{tabular}{lcccc}
\hline \multirow{2}{*}{ Stakeholder } & \multicolumn{2}{c}{ Urban } & \multicolumn{2}{c}{ Sub-Urban } \\
\cline { 2 - 5 } & $\begin{array}{c}\text { Jalan } \\
\text { Berbaya } \\
\text { r }\end{array}$ & $\begin{array}{c}\text { Parkir } \\
\text { Progre } \\
\text { sif }\end{array}$ & $\begin{array}{c}\text { Jalan } \\
\text { Berba } \\
\text { yar }\end{array}$ & $\begin{array}{c}\text { Parkir } \\
\text { Progre } \\
\text { sif }\end{array}$ \\
\hline Pelajar & 0,107 & 0,123 & 0,1 & 0,131 \\
\hline Pedagang & 0,077 & 0,154 & 0,138 & 0,092 \\
\hline
\end{tabular}




\begin{tabular}{lcccc}
\hline & \multicolumn{2}{c}{ Urban } & \multicolumn{2}{c}{ Sub-Urban } \\
\cline { 2 - 5 } Stakeholder & $\begin{array}{c}\text { Jalan } \\
\text { Berbaya } \\
\text { r }\end{array}$ & $\begin{array}{c}\text { Parkir } \\
\text { Progre } \\
\text { sif }\end{array}$ & $\begin{array}{c}\text { Jalan } \\
\text { Berba } \\
\text { yar }\end{array}$ & $\begin{array}{c}\text { Parkir } \\
\text { Progre } \\
\text { sif }\end{array}$ \\
\hline $\begin{array}{l}\text { Karyawan Swasta } \\
\text { / Pegawai Negri }\end{array}$ & 0,123 & 0,107 & 0,108 & 0,123 \\
Sipil & & & & \\
\hline $\begin{array}{l}\text { Ibu Rumah } \\
\text { Tangga }\end{array}$ & 0,115 & 0,115 & 0,22 & 0,107 \\
\hline Tukang Parkir & 0,077 & 0,094 & 0,1 & 0,131 \\
\hline $\begin{array}{l}\text { Decision Maker } \\
\text { Dan Influence }\end{array}$ & 0,154 & 0,132 & 0,096 & 0,135 \\
Group & & & & \\
\hline
\end{tabular}

\section{Sumber: Identifikasi, 2017}

Persentase banyaknya stakeholder di wilayah urban dan sub-urban yang memilih "kebijakan jalan berbayar" dan "kebijakan parkir progresif" dapat dilihat pada Gambar 4.1. Kebijakan parkir progresif di wilayah urban dipilih oleh pelajar (12\%), pedagang (15\%), petugas/tukang parkir (15\%) dan decision maker (13\% sedangkan karyawan swasta/PNS (12\%) lebih memilih kebijakan jalan berbayar. Di wilayah sub-urban kebijakan parkir progresif diilih oleh pelajar (13\%), karyawan swasta/PNS (12\%), petugas/tukang parkir (13\%) dan decision maker (13\%) sedangkan pedagang (14\%) dan ibu rumah tangga (12\%) lebih memilih kebijakan jalan berbayar.

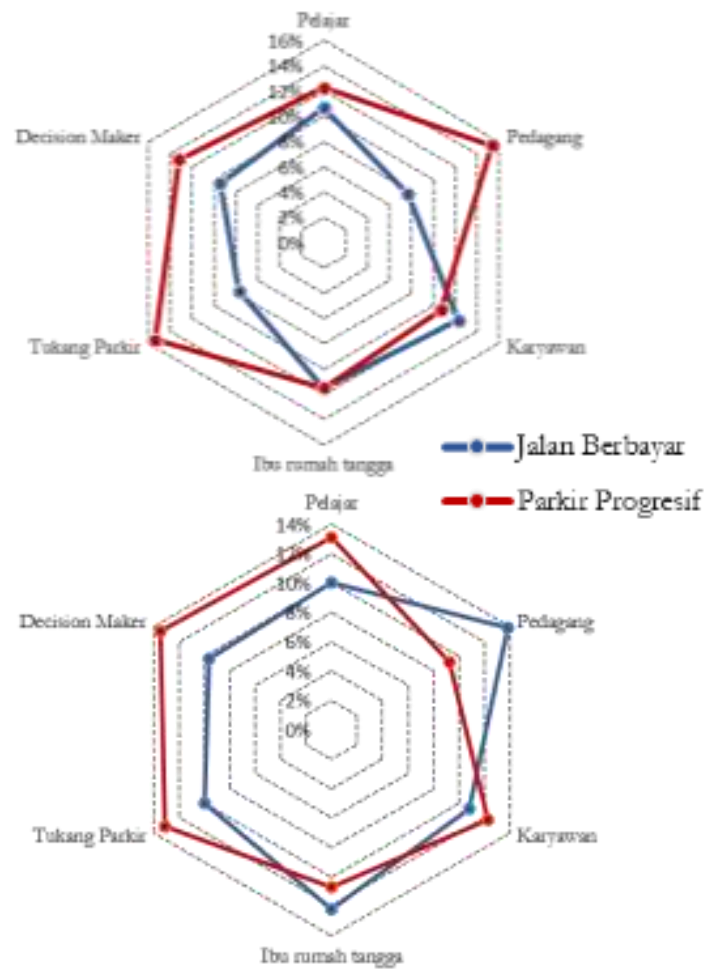

Gambar 1. Radar chart respon di urban (kiri) and sub-urban (kanan)

Sumber: Identifikasi (2017)

Selanjutnya dilakukan perhitungan menggunakan metode stated preference dengan bantuan SPSS untuk melihat signifikansinya, didapatkan hasil yaitu "kebijakan jalan berbayar" dan "kebijakan parkir progresif" di wilayah urban dan sub-urban signifikan berpengaruh terhadap respon scenario optimis (o,oo di wilayah urban dan -0,001 di wilayah sub-urban) dan scenario pesimis $(-0,001$ di wilayah urban dan -0,001 di wilayah sub-urban). Tabel 4.2 meunjukkan hasil pembentukan model dari perhitungan menghasilkan nilai "kebijakan jalan berbayar" lebih tinggi daripada "kebijakan parkir progresif".

Tabel 2

Hasil Perhitungan Stated Preference di Urban dan Sub urban area

\begin{tabular}{lcccccccc}
\multirow{2}{*}{ Variabel } & \multicolumn{3}{c}{ Skenario Optimis } & \multicolumn{3}{c}{ Skenario Pesimis } \\
\cline { 2 - 9 } & \multicolumn{2}{c}{ Urban } & \multicolumn{2}{c}{ Sub-Urban } & \multicolumn{2}{c}{ Urban } & \multicolumn{2}{c}{ Sub-Urban } \\
\cline { 2 - 9 } & B & Sig & B & Sig & B & Sig & B & Sig \\
& & & & $\cdot$ & & $\cdot$ & & $\cdot$ \\
\hline Jalan & 0,00 & 0 & - & 0 & - & 0 & - & 0 \\
Berbayar & & & 0,00 & & 0,001 & & 0,00 & \\
& & & 1 & & & & 1 & \\
\hline Parkir & - & 0 & - & 0 & - & 0 & - & 0 \\
Progresif & 0,001 & & 0,00 & & 0.00 & & 0,00 & \\
& & & 1 & & 2 & & 1 & \\
\hline Konstanta & 5,265 & 0 & 5,143 & 0 & 5,325 & 0 & 4.771 & 0 \\
\hline Sumber: Identifikasi, 2017 & & & & & &
\end{tabular}

2. Analisis Stakeholder

Tahap assessment berikutnya adalah mengelompokkan stakeholder berdasarkan tingkat kepentingan dan pengaruhnya, menggunakan modifikasi dari analisis terhadap kepentingan dan agenda stakeholder dan pengaruh stakeholder dilihat berdasarkan peran stakeholder dalam perumusan kebijakan manajemen permintaan transportasi.

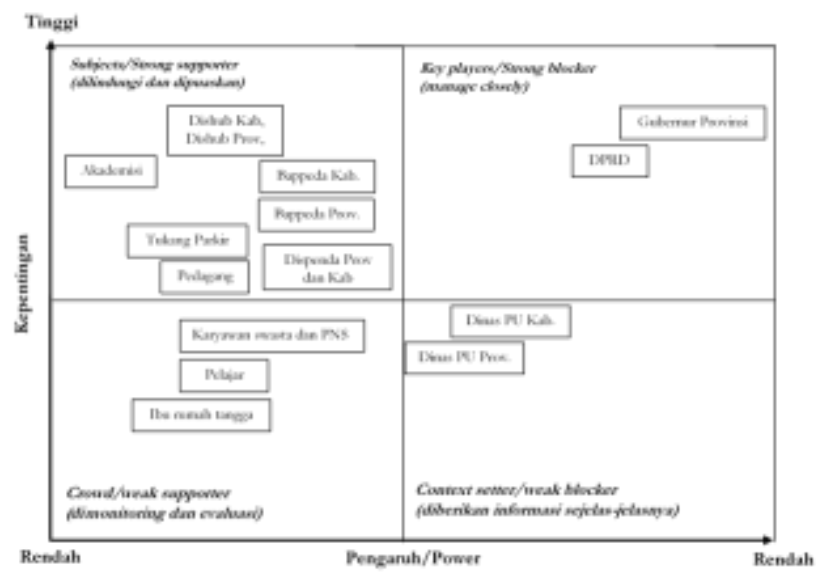

Gambar 2. Matriks kepentingan-pengaruh stakeholder dalam perumusan kebijakan transportasi

Sumber: Data primer/diolah (2017)

Langkah selanjutnya dalam analisis stakeholder adalah menganalisis tingkat hubungan antara stakeholder. Hubungan antar stakeholder dalam perumusan kebijakan transportasi yang teridentifikasi adalah konflik, saling mengisi dan bekerjasama. Stakeholder yang teridentifikasi dan menggambarkan hubungan antar stakeholder terlihat pada Tabel 3 .

Tabel 3

Tingkat hubungan antar stakeholder dalam perumusan kebijakan jalan berbayar dan parkir progresif

\begin{tabular}{lccc}
\hline & $\begin{array}{c}\text { Pemerintah } \\
\text { Daerah } \\
\text { (Decision } \\
\text { Maker) }\end{array}$ & $\begin{array}{c}\text { Masyara } \\
\text { kat } \\
\text { (Benefic } \\
\text { iaries) }\end{array}$ & $\begin{array}{c}\text { Akademisi } \\
\text { (Influence } \\
\text { Group) }\end{array}$ \\
\hline $\begin{array}{l}\text { Pemerintah } \\
\text { daerah }\end{array}$ & $1 ; 3$ & $1 ; 3$ & $2 ; 3$ \\
$\begin{array}{l}\text { Decision } \\
\text { maker) }\end{array}$ & $1 ; 3$ & $1 ; 2 ; 3$ & 3 \\
Masyarakat & $2 ; 3$ & 3 & $2 ; 3$
\end{tabular}


(Beneficiaries

)

Akademisi/LS

$\mathrm{M}$ (Influence

group)

Keterangan (Remarks):

1 = potensi konflik (potential conflict); 2 = potensi untuk saling

mengisi (potential to complement); 3 = potensi untuk

bekerjasama (potential for collaboration).

Sumber: Identifikasi, 2017

Tahapan selanjutnya yaitu analisis partisipasi stakeholder terhadap penerapan kebijakan melalui tabel matrik. Bertujuan melihat keterlibatan setiap stakeholder untuk mendukung keberhasilan proses perencanaan kebijakan.

\section{Tabel 4}

Partisipasi stakeholder terhadap kebijakan

\begin{tabular}{ccccc}
\hline TIPE & INFORM & KO & KERJASAMA & PENGA \\
PARTISIPA & ASI & NSU & & WASAN \\
SI/ & & LTA & & \\
\cline { 1 - 1 } TAHAPAN & & SI & & \\
PERENCA & & & &
\end{tabular}

\section{NAAN}

\begin{tabular}{|c|c|c|c|c|}
\hline $\begin{array}{l}\text { Identifika } \\
\text { si }\end{array}$ & & $\begin{array}{l}\text { Lem } \\
\text { baga } \\
\text { aka } \\
\text { dem } \\
\text { is/ } \\
\text { lem } \\
\text { baga } \\
\text { swa } \\
\text { sta } \\
\text { mas } \\
\text { yara } \\
\text { kat }\end{array}$ & $\begin{array}{l}\text { - Gubernur, } \\
\text { DPRD, } \\
\text { - Bappeda } \\
\text { Provinsi } \\
\text { dan } \\
\text { Kabupaten, } \\
\text { - Dinas } \\
\text { Perhubung } \\
\text { an } \\
\text { Kabupaten } \\
\text { dan } \\
\text { Provinsi, } \\
\text { - Dinas } \\
\text { Pekerjaan } \\
\text { umum } \\
\text { Provinsi }\end{array}$ & \\
\hline $\begin{array}{l}\text { Perencan } \\
\text { aan }\end{array}$ & $\begin{array}{l}\text { Dinas } \\
\text { Pekerjaan } \\
\text { umum } \\
\text { Provinsi } \\
\text { dan } \\
\text { Kabupate } \\
\text { n }\end{array}$ & & $\begin{array}{l}\text { - } \text { Bappeda } \\
\text { Provinsi } \\
\text { dan } \\
\text { Kabupaten, } \\
\text { - Dinas } \\
\text { Perhubung } \\
\text { an } \\
\text { Kabupaten } \\
\text { dan } \\
\text { Provinsi, } \\
\text { - Dinas } \\
\text { Pekerjaan } \\
\text { umum } \\
\text { Provinsi } \\
\text { dan } \\
\text { Kabupaten, } \\
\text { - Lembaga } \\
\text { akademik }\end{array}$ & \\
\hline $\begin{array}{l}\text { Implemen } \\
\text { tasi }\end{array}$ & $\begin{array}{l}\text { Lembaga } \\
\text { akademis } \\
\text { / } \\
\text { lembaga } \\
\text { swasta } \\
\text { masyarak } \\
\text { at }\end{array}$ & \begin{tabular}{l}
\multicolumn{1}{c}{ Din } \\
as \\
Pek \\
erja \\
an \\
umu \\
m \\
Prov \\
insi \\
dan \\
Kab \\
upat \\
en
\end{tabular} & $\begin{array}{l}\text { - } \text { Bappeda } \\
\text { Provinsi } \\
\text { dan } \\
\text { Kabupaten, } \\
\text { - Dinas } \\
\text { Perhubung } \\
\text { an } \\
\text { Kabupaten } \\
\text { dan } \\
\text { Provinsi, } \\
\text { - Dinas } \\
\text { Pekerjaan } \\
\text { umum } \\
\text { Provinsi }\end{array}$ & $\begin{array}{l}\text { Gubernu } \\
\mathrm{r}\end{array}$ \\
\hline
\end{tabular}

\begin{tabular}{|c|c|c|c|}
\hline & & & $\begin{array}{l}\text { dan } \\
\text { Kabupaten, } \\
\text { - Dinas } \\
\text { Pendapata } \\
\text { n Daerah } \\
\text { Provinsi } \\
\text { dan } \\
\text { Kabupaten, }\end{array}$ \\
\hline $\begin{array}{l}\text { Monitorin } \\
\text { g dan } \\
\text { Evaluasi }\end{array}$ & $\begin{array}{l}\text { Pelajar, } \\
\text { Pedagang } \\
\text { Karyawa } \\
\text { n } \\
\text { swasta/P } \\
\text { NS, Ibu } \\
\text { rumah } \\
\text { tangga, } \\
\text { tukang } \\
\text { parkir }\end{array}$ & $\begin{array}{l}\text { Din } \\
\text { as } \\
\text { Pek } \\
\text { erja } \\
\text { an } \\
\text { umu } \\
\text { m } \\
\text { Prov } \\
\text { insi } \\
\text { dan } \\
\text { Kab } \\
\text { upat } \\
\text { en }\end{array}$ & $\begin{array}{l}\text { Gubernur, } \\
\text { DPRD, Dinas } \\
\text { Pekerjaan } \\
\text { umum Provinsi } \\
\text { dan Kabupaten }\end{array}$ \\
\hline
\end{tabular}

\section{DISKUSI}

Penelitian ini menunjukan bukti bahwa instrument "kebijakan parkir progresif" adalah kebijakan yang paling diterima oleh seluruh stakeholder, baik di wilayah urban maupun sub urban. Secara umum, "kebijakan parkir progresif" memang paling diterima tetapi dalam konteks segmentasi stakeholder, ada beberapa yang memiliki pandangan berbeda. Berdasarkan hasil analisis stakeholder,maka kelompok stakeholder yang berpotensi menjadi strong blocker yaitu Gubernur provinsi, dan DPRD sebagai key player memiliki kepentingan dan pengaruh yang tinggi terhadap penerapan "kebijakan parkir progresif”. Selain itu, kepentingan mereka terhadap kebijakan parkir progresif harus di managed closely agar tujuan kebijakan tetap sesuai tanpa ada kepentingan lain yang dapat mempengaruhi seperti politik.

Singkatnya, penelitian ini menjadi bukti bahwa "kebijakan parkir progresif" lebih baik diimplementasikan daripada "kebijakan jalan berbayar" di kota yang sedang berkembang sebagai alternatif solusi untuk mengurangi jumlah lalu lintas khususnya kendaraan pribadi yang masuk akibat pembangunan infrastruktur jembatan. Temuan ini akan menambah keyakinan bahwa dari segi stakeholder akan lebih diterima dan dari segi teknis akan lebih mudah untuk diimplementasikan, karena menyesuaikan dengan sumber daya yang ada.

\section{E. SIMPULAN DAN SARAN}

Penelitian ini membuktikan bahwa "kebijakan parkir progresif" lebih baik dari pada "kebijakan jalan berbayar" di kota-kota yang sedang berkembang ketika ingin mencegah dampak negative dari pembangunan infrastruktur jembatan. Tendensi tersebut adalah sebagai berikut. Pertama, dari segi stakeholder kebijakan parkir progresif lebih diterima. Sehingga nantinya diperkirakan dapat meminimalkan terjadinya konflik antar stakeholder. Kedua, dari segi teknis akan lebih 
mudah dibandingkan dengan jalan berbayar yang membutuhkan integrasi dengan teknologi informasi, mengingat di kota yang sedang berkembang sarana dan prasarana masih belum memadai, banyaknya jaringan jalan akan membuat sulit dalam menentukan gate perekam ketika harus menerapkan jalan berbayar. Ketiga, dari hasil analisis matrix actor linkage diketahui bahwa tingkat hubungan antara pemangku kepentingan bersifat potensi konflik, kerjasama dan melengkapi yaitu di antara pemerintah pusat, pemerintah daerah, masyarakat, LSM dan lembaga akademis. Dengan demikian, strategi yang dapat diterapkan untuk mengoptimalkan pengaturan pemangku kepentingan dalam perwujudan "kebijakan parkir progresif" adalah melalui peningkatan koalisi, kolaborasi dan kerja sama antara subject dan key players yang memiliki tingkat kepentingan yang tinggi terhadap kebijakan parkir progresif. Hal ini dapat terwujud melalui peningkatan kerjasama dan kolaborasi yang efektif antara pemerintah daerah dan Dinas terkait dalam perwujudan 'kebijakan parkir prgogesif" dan praktik pengaturan kebijakan transportasi saat ini.

\section{DAFTAR RUJUKAN}

[1] Murray, A., Effects of toll removal on Tauranga Harbour Bridge

[2] Apriyanti, E., 2016. Kajian pengaruh jembatan kapuas terhadap lalu lintas air maupun darat di kota sintang

[3] Broaddus, A., 2009. Transportation Demand Management Plan for.

[4] Litman, T. \& Burwell, D., 2006. Issues in sustainable transportation. International Journal of Global Environmental Issues, 6(4), pp.331-347.

[5] Santos, G., Li, W.W. \& Koh, W.T.H., 2004. 9. Transport Policies in Singapore. Research in Transportation Economics, 9(4), pp.209-235.

[6] Teubel \& Schlag, B., 1997. Public acceptability of transport pricing. Structure, 21, pp.1-17.

[7] Balcombe, R. et al., 2004. The demand for public transport: a practical guide. Transport Policy, 13, pp.295-306.

[8] Pierce, G., Willson, H. \& Shoup, D., 2015. Optimizing the use of public garages: Pricing parking by demand. Transport Policy, 44, pp.89-95.

[9] Schade, J., 2000. Acceptability of Urban.

[10]Coser, L.A., 2007. No Title. Social Conflict and the Theory of Social Change, 8(3), pp.197-207.

[11] Broaddus, A., Litman, T. \& Menon, G., 2010. Manajemen Permintaan Transportasi. , p.13o.

[12] Overseas Development Administration. 1995. Guidance note on how to do stakeholder analysis of aid projects and programmes. Bonn: Social Development Departement, Overseas Development Administration. Diunduh 11 Desember 2016 dari http://www.euforic.org/gb/stake1.htm\#intro 